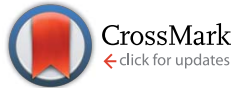

Cite this: RSC Adv., 2015, 5, 12300

Received 12th November 2014 Accepted 9th January 2015

DOI: 10.1039/c4ra14404j

www.rsc.org/advances

\section{Solid-state NMR studies of nucleic acid components}

\begin{abstract}
Martin Dračínský ${ }^{\star a}$ and Paul Hodgkinson ${ }^{b}$
Recent applications of solid-state NMR to the characterisation of nucleic acid systems are reviewed. Developments in NMR methodology and DFT-based first-principles calculations have led to the emergence of "NMR crystallography", where solid-state NMR provides information on local structure and dynamics that complements information on periodic ordering and overall structure provided by traditional diffraction crystallography. The solid-state NMR is shown to provide direct information on hydrogen-bonding arrangements, metal ion interactions and local molecular dynamics that is difficult to obtain by other techniques, including solution-state NMR.
\end{abstract}

\section{Introduction}

Nucleotides, oligonucleotides and nucleic acids are fascinating molecules that are responsible for many cellular processes such as the storage of genetic information, catalysis, metabolic regulation and energy supply. ${ }^{1}$ Furthermore, chemical modifications of the components of nucleic acids open up new ways of fighting many diseases, such as AIDS or cancer., ${ }^{2,3}$

At first sight, using NMR to study solid nucleic acid components may seem somewhat perverse. Lack of motional averaging in the solid state means that NMR spectra of solids generally exhibit significantly poorer resolution than their solution-state counterparts, and it is generally the behaviour of nucleic acids in in vivo conditions rather than as solids that is of

${ }^{a}$ Institute of Organic Chemistry and Biochemistry, Flemingovo nám. 2, 16610, Prague, Czech Republic. E-mail: dracinsky@uochb.cas.cz

${ }^{b}$ Department of Chemistry, Durham University, South Road, DH1 3LE, Durham, UK most biological interest. However, the overall re-orientational dynamics of molecules in solution significantly complicates the interpretation of solution-state NMR results. Moreover, the polyanionic nature of nuclei acids means that their solid forms are usually well hydrated and the local environments (which NMR probes) are, as a result, not too dissimilar from in vivo conditions. Solid-state NMR (SS-NMR) is now widely used as complement to classical diffraction methods of characterising solid materials, with Bragg diffraction providing the overall long-range structure and NMR providing information on aspects, such as hydrogen atom positioning and dynamics, that are difficult to characterise by diffraction. This field is commonly termed "NMR crystallography", although it is important to note that NMR techniques are not limited to crystalline solids. Solid-state NMR has the great virtue that chemical shifts can be determined for solid materials of known structure, permitting the correlation of the NMR parameters directly with structural features. ${ }^{4,5}$ Solid-state NMR is thus a

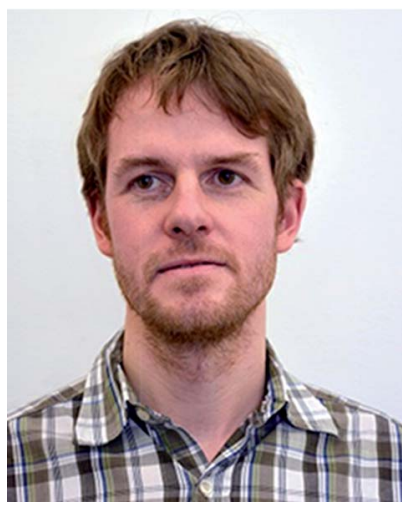

Martin Dračinský obtained his PhD in organic chemistry from Charles University in Prague in 2006. He is currently working as a researcher at Czech Academy of Sciences. His research deals with experimental solution and solid-state NMR spectroscopy applied mostly to modified nucleic acid components, theoretical prediction of NMR parameters (including vibrational and solvent effects) and classical and DFT molecular dynamics simulations.

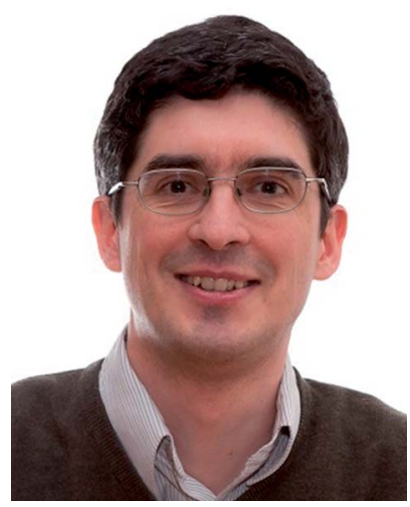

Paul Hodgkinson obtained his PhD in physical chemistry from Oxford University in 1995, and, following postdoc periods as UC Berkeley and the ENS de Lyon, has been working at Durham University's Department of Chemistry since 1998, where he is now a Reader in Magnetic Resonance. His research group works in both on the fundamental principles of solid-state NMR as well as applications to chemical problems, focussing on the use of quantum calculation to enable the "NMR crystallography" of molecular organic solids. 
valuable tool for nucleoside and nucleotide structural studies since it provides the means to acquire spectra corresponding to single conformations, in contrast to solution NMR methods.

The fundamental concepts of solid-state NMR have been extensively described, ${ }^{6-8}$ and only summarised very briefly here. The various interactions of NMR are fundamentally anisotropic with respect to the strong magnetic field applied during the NMR experiment. In the solution state, however, fast molecular tumbling means that only the isotropic average of the interactions is observed via the NMR spectrum. Interactions with no isotropic component, such as the direct dipolar interaction between nuclear magnetic moments, and the quadrupolar interaction (due to coupling between nuclear electric quadrupole moments and local electric field gradients) have no effect on the spectrum, leaving just the isotropic components of the chemical shift and indirect (or J) coupling. This leads to sharp well-resolved solution-state spectra for spin-1/2 nuclei, such as ${ }^{1} \mathrm{H}$ and ${ }^{13} \mathrm{C}$. This same molecular tumbling is an efficient driver of relaxation processes. This can be an asset, returning the spin states quickly to equilibrium and allowing the NMR experiment to be repeated quickly, but it can be problematic for nuclei with a significant electric quadrupole moment; rapid quadrupolar relaxation will typically lead to broad and unresolved lines for potentially useful nuclei such as ${ }^{23} \mathrm{Na}$. In contrast, the lack of extensive dynamics in the solid state means that NMR spectra of solid materials are strongly broadened by the anisotropic interactions. This broadening can be significantly reduced by the use of "magic-angle spinning" (MAS), which averages out, at least to first order, the anisotropic components of the NMR interactions. The extensive nature of dipolar coupling between ${ }^{1} \mathrm{H}$ nuclei means that ${ }^{1} \mathrm{H}$ NMR spectra of solids are still relatively poorly resolved, even at the fastest MAS spinning rates currently available (about $100 \mathrm{kHz}$ ), and so the initial nucleus of choice for organic systems is generally ${ }^{13} \mathrm{C}$. In contrast, specialised NMR techniques, such as the Multiple Quantum MAS (MQMAS) experiment, often allow better site resolution for nuclei such as ${ }^{23} \mathrm{Na}$ to be obtained in the solid compared to the solution state. Similarly ${ }^{2} \mathrm{H}$ NMR is a powerful technique for studying dynamics since the deuterium quadrupolar coupling is both small enough to be readily measured and highly sensitive to local dynamic processes. Dynamics of nucleic acids has been studied by ${ }^{2} \mathrm{H}$ NMR for more than 30 years; early studies were reviewed in 1991. ${ }^{9}$ In contrast to other techniques (solution NMR, X-ray), solid-state NMR can probe motions with a broad range of time scales. Other specialised experiments, most notably REDOR ${ }^{\mathbf{1 0}}$ experiments as discussed below, have been developed that allow dipolar couplings between pairs of nuclear spins to be measured directly. These provide more robust estimates of internuclear distances than the indirect estimation of dipolar couplings from "nuclear Overhauser effects" in the solution state.

In addition to methodological advances, the development of "NMR crystallography" has been driven by the availability of DFT calculations that allow NMR properties to be calculated efficiently. ${ }^{11,12}$ Such quantum calculations provide a direct link between structure and NMR observables; rather than the NMR spectrum simply being used as a fingerprint of a particular solid-form, it is now possible to relate structural and NMR parameters in a quantitative fashion. Several modelling and simulation techniques have been proposed to describe the influence of intermolecular interactions in the solid state on chemical shifts. In the cluster model, neighbouring molecules or fragments are considered explicitly during the chemicalshielding calculations. However, modelling a solid as a 'large molecule' or a cluster has many difficulties. The choice of the cluster, in particular its termination, is critical, as the calculations must be maintained at a manageable size. It is thus more efficient to exploit the translational repetition in crystals. In the last decade, the gauge-including projector-augmented wave (GIPAW) procedure has been developed for the prediction of the magnetic-resonance parameters in fully periodic solids. ${ }^{13}$ The wide applications of GIPAW-based calculations to "NMR crystallography" are now well documented. ${ }^{12,14}$ Note also that nucleic acid components have often been used as model compounds for the development and testing of computational methods. For example, the GIPAW approach has been tested against cluster calculations for solid isocytosine, where the cluster modelling was clearly found to be inferior. ${ }^{15}$

In this paper, we review recent applications (mostly after 2000) of solid-state NMR and NMR crystallography in studies of the structure of nucleic acid components, their intra- and intermolecular interactions, and dynamics.

\section{Structure of nucleic acids components}

One of the major conformational variables in nucleic acids is the pucker of the (deoxy)ribose ring. High-resolution X-ray studies have shown that the most common ring conformations in DNA are $3^{\prime}$-endo and 2 -endo. The pucker is inextricably linked to the helix geometry. For instance, the conformation is $\mathrm{C} 2$ '-endo and $\mathrm{C} 3$ '-endo in the B-form and the A-form of DNA respectively. The conformations of individual monomers in nucleic acids are thus important for their biological function.

In the determination of nucleic acid structure by solutionstate NMR, the backbone has a relatively low density of constraints because of the difficulty of obtaining conformational parameters from $\mathrm{J}$ couplings or NOE information within crowded spectral regions, particularly for large nucleic acids. For example, determining the backbone torsion angle $\gamma\left(\mathrm{O5}^{\prime}{ }^{-}\right.$ $\left.\mathrm{C}^{\prime}-\mathrm{C}^{\prime}-\mathrm{C} 3^{\prime}\right)$ from ${ }^{3} \mathrm{~J}_{\mathrm{HH}}$ through the measurement of $\mathrm{J}_{\mathrm{H} 4^{\prime}-\mathrm{H} 5^{\prime}}$ and $\mathrm{J}_{\mathrm{H} 4^{\prime}-\mathrm{H} 5^{\prime \prime}}$ is often impractical because of the severe spectral overlapping of $\mathrm{H}^{\prime}$ and $\mathrm{H}^{\prime \prime}$ resonances, the difficulty in their stereo assignment, as well as poor detection because of the proximity of the water peak. ${ }^{16}$ Fig. 1 shows the conventional nucleotide atom numbering and torsion angle definitions.

In the solid, all of the major forms of DNA are accessible, either as fibres or as crystalline oligomers. In addition, crystalline nucleosides and nucleotides with a variety of ring puckers are known. Chemical shifts for a series of solid nucleosides and nucleotides with different deoxyribose ring conformations have been measured and the ${ }^{13} \mathrm{C}$ chemical shifts were found to be related in a direct way to the ring pucker; $3^{\prime}$-endo conformers have significantly lower $\mathrm{C} 3^{\prime}$ and $\mathrm{C}^{\prime}$ chemical shifts (5-10 ppm) relative to comparable $3^{\prime}$-exo and $2^{\prime}$-endo 


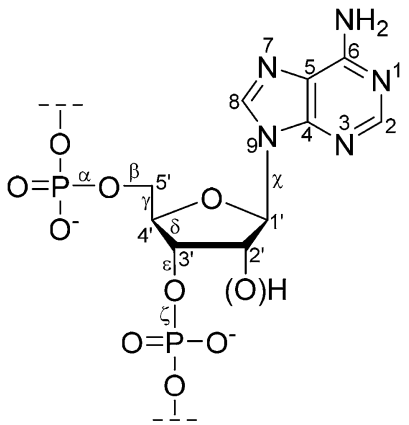

Fig. 1 The structure of a $\left(2^{\prime}\right.$-deoxy)ribonucleotide fragment with atom numbering and selected torsion angles.

conformers. ${ }^{4}$ The latter two conformers were distinguished by smaller, but still significant, differences in the carbon chemical shifts at the $\mathrm{C}^{\prime}{ }^{\prime}$ and $\mathrm{C}^{\prime}{ }^{\prime}$ positions. The same trends have also been observed for chemical shifts calculated by DFT methods for isolated nucleosides. ${ }^{17}$ CP-MAS NMR spectroscopy has also been used to investigate the dependence of ${ }^{13} \mathrm{C}$ chemical shifts on specific conformational parameters of a variety of RNA nucleosides and nucleotides. It was shown that ${ }^{13} \mathrm{C}$ chemical shifts can be used to determine sugar pucker and glycosidic $(\chi)$ and exocyclic $(\gamma)$ angles in these systems with a high degree of certainty. ${ }^{18}$

Similarly, the dependence of ${ }^{13} \mathrm{C}$ chemical shifts of the sugar ring on backbone torsion angle $\gamma\left(\mathrm{O}^{\prime}-\mathrm{C}^{\prime}-\mathrm{C}^{\prime}-\mathrm{C} 3^{\prime}\right)$ and $\delta\left(\mathrm{C}^{\prime}-\right.$ $\left.\mathrm{C} 4^{\prime}-\mathrm{C}^{\prime}-\mathrm{O}^{\prime}\right)$ as well as the sugar pucker, has been determined using crystalline nucleosides and nucleotides. The experimental data agreed well with DFT-calculated chemical shifts, implying that ${ }^{13} \mathrm{C}$ chemical shifts are a useful tool for the determination of nucleic acid structure. The chemical shifts of $\mathrm{C}^{\prime}, \mathrm{C}^{\prime}$, and $\mathrm{C5}^{\prime}$ may be used for a reliable determination of the backbone torsion angles and the sugar pucker in most cases. ${ }^{16}$

An unusual DNA structure in Pf1 bacteriophage has been characterised by solid-state NMR. On the basis of experimental chemical shifts, obtained with dynamic-nuclear-polarisationenhanced spectroscopy, it was concluded that Pf1 DNA exhibits a $2^{\prime}$-endo conformation because of its high $\mathrm{C}^{\prime}$ and $\mathrm{C}^{\prime}$ chemical shifts. The ${ }^{13} \mathrm{C}$ and ${ }^{15} \mathrm{~N}$ chemical shifts of the DNA bases fall outside their typical regions in DNA, pointing to an absence of Watson-Crick hydrogen bonding. ${ }^{19}$ For example, adenine $\mathrm{C} 4$ and $\mathrm{C} 5$, and thymine $\mathrm{C} 2$ and $\mathrm{C} 5$ had unusually high chemical shifts, falling 1-2 ppm above the range of chemical shifts observed in B-DNA and cytosine C4, and guanosine C4 and C5 had unusually low chemical shifts. These observations were consistent with the absence of hydrogen bonding previously observed for thermal melting of DNA duplexes. ${ }^{20}$

The chemical shift of the ${ }^{31} \mathrm{P}$ nucleus in the backbone of nucleic acids is influenced by the torsion angle $\zeta$, which, at least in the B-type of nucleic acids, is either in the gauche region (approximately $-60^{\circ}$, BI class) or in the trans region (approximately $180^{\circ}$, BII class). A phosphorus isotropic chemical shift difference of $1.8 \mathrm{ppm}$ between the two classes has been extracted from ${ }^{31} \mathrm{P}$ CP-MAS spectra of model solid oligonucleotides, the BII phosphorus atom having higher chemical shift than the BI. ${ }^{21}$ This study used macroscopically oriented samples, with fibres parallel to the rotor axis, allowing the orientation of the phosphate group with respect to the fibre axis to be determined. Although the BI $\leftrightarrow$ BII conformational exchange is always fast in solution, a range of ${ }^{31} \mathrm{P}$ shifts is observed in solution which is consistent with some systems existing predominantly in one conformation and others in a distribution, with the average ${ }^{31} \mathrm{P}$ shift being determined by the $\mathrm{BI} / \mathrm{BII}$ ratio. ${ }^{22,23}$

Chemical shift information can, however, be difficult to interpret due to non-local effects. Torsion angles may be more directly estimated by solid-state NMR using experiments that are sensitive to the relative orientations of nuclear spin interaction tensors. For example, experiments exploiting the evolution of a double quantum coherence under the heteronuclear local fields of neighbouring spins have been used to measure the $\delta$ torsion angles of two $2^{\prime}$-deoxynucleosides doubly ${ }^{13} \mathrm{C}$-labelled at the $\mathrm{C} 3^{\prime}$ and $\mathrm{C} 4{ }^{\prime}$ positions. ${ }^{24}$ Similarly, the $\mathrm{H} 1^{\prime}-$ $\mathrm{C}^{\prime}$-C6-H6 projection torsion angle defining the relative orientation of the nucleoside pyrimidine and ribose rings in uniformly labelled $\left[{ }^{13} \mathrm{C},{ }^{15} \mathrm{~N}\right]$ uridine has been estimated by selective excitation of ${ }^{13} \mathrm{C}$ double-quantum coherences under MAS at rotational resonance. ${ }^{25}$

Rotational echo double resonance (REDOR) is a solid-state NMR technique used to measure dipolar couplings and hence distances between pairs of different nuclear spins, which is frequently applied to biological structure problems. The distance range accessible by REDOR generally exceeds that of NOE or residual dipolar coupling measurements in solution. For example, the high magnetogyric ratio of ${ }^{31} \mathrm{P}$ and ${ }^{19} \mathrm{~F}$ nuclei means that ${ }^{31} \mathrm{P},{ }^{19} \mathrm{~F}$ dipolar couplings are relatively strong, and ${ }^{31} \mathrm{P}-{ }^{19} \mathrm{~F}$ distances of up to $16 \AA$ have been measured. ${ }^{26}$ The high number of the phosphodiesters in the backbone of nucleic acids results in poorly resolved ${ }^{31} \mathrm{P}$ NMR spectra. To enable sitespecific detection of ${ }^{31} \mathrm{P}-{ }^{19} \mathrm{~F}$ distances, a single phosphate group has been replaced by a phsphorothioate group, and fluorinated nucleotides have been placed in specific positions of model oligonucleotides. $.^{27}{ }^{31} \mathrm{P}-{ }^{19} \mathrm{~F}$ REDOR has also been used to monitor changes in minor groove width of a DNA oligomer upon binding of the drug distamycin A at different stoichiometries (Fig. 2). ${ }^{28}$

Frequency-selective ${ }^{31} \mathrm{P}-{ }^{13} \mathrm{C}$ REDOR has been used to determine $\mathrm{P} \alpha-\mathrm{C} 8, \mathrm{P} \beta-\mathrm{C} 8$, and $\mathrm{P} \gamma-\mathrm{C} 8$ distances in ATP within the Na, K-ATPase enzyme. These distances were then used to propose the ATP conformation in the enzyme. ${ }^{29}$ These distances were compatible with a previous ${ }^{13} \mathrm{C}$-detected proton spin diffusion experiment, which was used to detect contacts between ATP and the binding site of the enzyme. The $\mathrm{P}-\mathrm{C}$ distances followed the order $\mathrm{C} 2>\mathrm{C} 8>$ ribose, which is consistent with the adenine ring of ATP being in contact with the binding site and the ribose ring being relatively exposed..$^{30}$

Solid-phase synthesis has become the method of choice for producing oligonucleotides of defined sequence. ${ }^{31} \mathrm{P}$ CP-MAS experiments have been used to monitor the solid-phase oligonucleotide-elongation reactions. The technique readily distinguishes the oxidation state of the phosphorus atom (phosphate/phosphite), the presence or absence of a protecting 


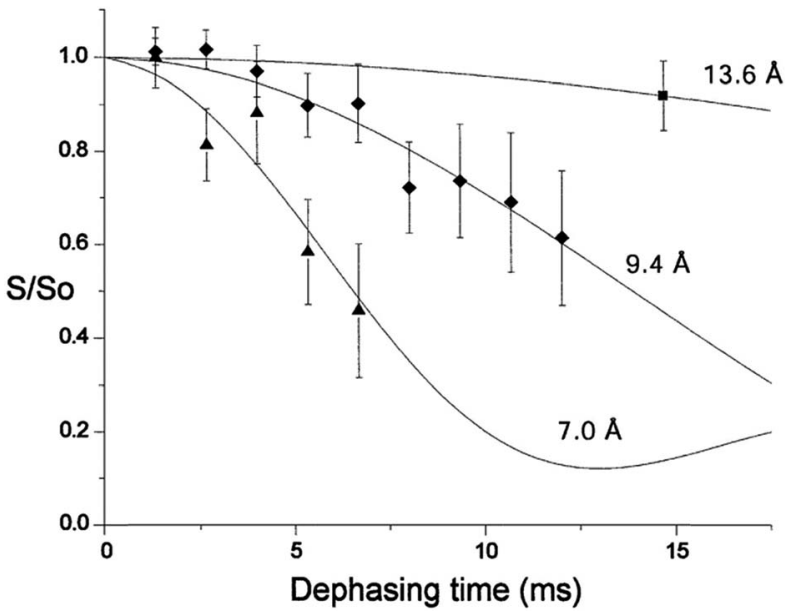

Fig. $2{ }^{31} \mathrm{P}-{ }^{19} \mathrm{~F}$ REDOR dephasing curves for a selectively fluoro- and phosphorothioate-substituted DNA and its $1: 1$ and $2: 1$ distamycin complexes. Solid lines represent expected decay curves based on simulations. Diamonds mark data for the unbound DNA, triangles for the $1: 1$ distamycin: DNA complex and the square for the $2: 1$ distamycin : DNA complex. ${ }^{28}$ Copyright Oxford University Press. Reproduced with permission.

group attached to phosphorus, or phosphate vs. phosphorothioate groups. ${ }^{31}$ Similarly, ${ }^{31} \mathrm{P}$ CP-MAS experiments have been used to study the complexation of $2^{\prime}$-deoxyadenosine-5'-phosphate (dAMP) with the surface of a mesoporous aluminium oxide. A single ${ }^{31} \mathrm{P}$ resonance was observed upon complexation. However, ${ }^{27} \mathrm{Al}$ MAS spectra show both tetrahedral and octahedral aluminium environments expected for the mesoporous alumina. ${ }^{27} \mathrm{Al}-{ }^{31} \mathrm{P}$ REDOR experiments revealed that the phosphate group of dAMP interacts predominantly with the octahedrally coordinated aluminium species at the surface. A comparison of experimental ${ }^{31} \mathrm{P}$ CSA tensor parameters (obtained by the analysis of spinning side-bands) with those calculated for model clusters indicated that the binding was via a monodentate complex. ${ }^{32}$

\section{Hydrogen bonding}

The potential of nucleobases to form well-defined hydrogenbonded base pairs is not only a major determinant of nucleic acid structure, but is also fundamental to important biological processes, such as replication and transcription. In addition, hydrogen-bond interactions between nucleobases and amino acid side chains are believed to play a crucial role in the recognition of specific nucleotide sequences by DNA-binding proteins. ${ }^{33,34}$ Detailed characterization of hydrogen bond interactions between biomolecular building blocks has, therefore, been the subject of numerous experimental and theoretical studies. NMR spectroscopy is one of the most powerful tools to study the strength and geometry of hydrogen bonds, although the study of hydrogen-bond interactions of small molecules by NMR is often hampered by the fast exchange of species in solution. Useful insight into the hydrogen bond strength and geometry is also obtained by comparing experimental NMR parameters with theoretical predictions. ${ }^{35,36}$
Solid-state NMR has recently been used to identify ribbonlike and quartet-like self-assembly in guanosine derivatives by means of ${ }^{1} \mathrm{H}$ chemical shifts and proton-proton proximities, as identified in ${ }^{1} \mathrm{H}$ double-quantum/single-quantum correlation experiments (which used combined rotation and multiple-pulse spectroscopy (CRAMPS) to improve ${ }^{1} \mathrm{H}$ spectral resolution). The $\mathrm{NH}$ proton chemical shift was observed to be higher (13$15 \mathrm{ppm}$ ) for ribbon-like self-assembly compared to $10-11 \mathrm{ppm}$ for a quartet-like arrangement, corresponding to a change from $\mathrm{NH} \cdots \mathrm{N}$ to $\mathrm{NH} \cdots \mathrm{O}$ intermolecular hydrogen bonding. ${ }^{37}$ Hydrogen-bond networks in organosilicas based on adenine and thymine have also been studied by ${ }^{1} \mathrm{H}$ solid-state NMR; spatial connectivities between protons were established using ${ }^{1} \mathrm{H}-{ }^{1} \mathrm{H}$ double quantum MAS experiments, allowing the geometries of hydrogen-bonded base pairs to be determined. ${ }^{38}$

Solid isocytosine provides an unusual opportunity to study two different tautomers of isocytosine, as they crystallize in a $1: 1$ ratio in a manner similar to that of the guanine and cytosine pairs in DNA. A combination of X-ray with solid-state NMR spectroscopic data and GIPAW calculations enabled precise structural parameters to be obtained, such as the geometries of intermolecular hydrogen bonds between isocytosine molecules, and by analogy Watson-Crick nucleic acid G-C base pairs. ${ }^{1} \mathrm{H}$ chemical shifts of free $\mathrm{NH}$ and $\mathrm{NH}$ involved in the intermolecular hydrogen bond differ by 3 ppm (Fig. 3). In solution, the tautomers of isocytosine are in a fast equilibrium, and only averaged NMR parameters can be obtained. ${ }^{15}$

Weak hydrogen bonding $\mathrm{C}-\mathrm{H} \cdots \mathrm{O}$ in solid uracil has been investigated in a study that related experimentally determined ${ }^{1} \mathrm{H},{ }^{13} \mathrm{C}$, and ${ }^{15} \mathrm{~N}$ chemical shifts with first-principles calculations. The effects of intermolecular interactions were quantified by comparing shifts calculated for isolated molecules, molecular planes, and a full crystal. Isolated molecule to plane changes in the ${ }^{1} \mathrm{H}$ chemical shifts of $2 \mathrm{ppm}$ were determined for the $\mathrm{CH}$ protons involved in the weak hydrogen bonding; this compares to changes of $c a .5 \mathrm{ppm}$ for the $\mathrm{NH}$ protons involved in conventional $\mathrm{NH} \cdots \mathrm{O}$ hydrogen bonding. ${ }^{39}$ Similarly, the effects of conventional and weak hydrogen bonds on the principal components of ${ }^{1} \mathrm{H},{ }^{13} \mathrm{C}$, and ${ }^{15} \mathrm{~N}$ chemical shift tensors and ${ }^{14} \mathrm{~N}$ and ${ }^{17} \mathrm{O}$ electric field gradients of uracil atoms have been

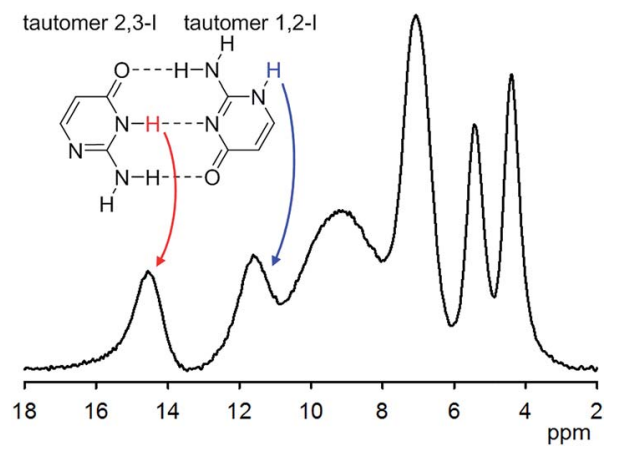

Fig. $3{ }^{1} \mathrm{H}$ NMR spectrum of solid isocytosine acquired at $65 \mathrm{kHz}$ MAS. Two tautomers in $1: 1$ ratio are present in the solid form. The chemical shift of the hydrogen-bound $\mathrm{NH}$ is substantially different from that of the free $\mathrm{NH}$. 
determined experimentally (for ${ }^{13} \mathrm{C}$ and ${ }^{15} \mathrm{~N}$ ) and computationally. ${ }^{40}$

The very low natural abundance of ${ }^{17} \mathrm{O}$ limits oxygen NMR studies of nucleic acids components to ${ }^{17} \mathrm{O}$-enriched samples. For example, ${ }^{17} \mathrm{O}$ NMR parameters have been determined for site-specifically ${ }^{17} \mathrm{O}$-enriched nucleic acid bases. ${ }^{41-43}$ The ${ }^{17} \mathrm{O}$ NMR tensors were found to be highly sensitive to the nature of the intermolecular interactions in the solid state. The solidstate NMR determination of NMR interaction tensors of the carbonyl oxygen (O6) of guanine in two ${ }^{17} \mathrm{O}$-enriched guanosine derivatives has been reported. The ${ }^{17} \mathrm{O}$ chemical-shift tensor and quadrupolar-coupling tensor were found to be very sensitive to the presence of hydrogen bonding and ion-carbonyl interactions, with the effect from ion-carbonyl interactions being several times stronger than that from hydrogen-bonding interactions. ${ }^{44}$

Although J couplings are not normally resolved in solid-state NMR spectra (because the observed linewidth is usually larger than the magnitude of the coupling), spin-echo based experiments often allow J couplings as small as $3.8 \mathrm{~Hz}$ to be measured. ${ }^{45,46}$ A powerful application of the spin-echo MAS technique is the quantification of hydrogen-bond mediated ${ }^{2 \mathrm{~h}} \mathrm{~J}_{\mathrm{NN}}$ couplings, since it allows the identification of hydrogenbonded partners, as well as the quantification of hydrogenbond strengths and geometries. ${ }^{47}$ The detection of hydrogen bonds in the solid state via correlation peaks due to hydrogenbond-mediated $\mathrm{J}$ coupling in a ${ }^{15} \mathrm{~N}$ refocused INADEQUATE spectrum has been reported for two guanosine derivatives. It was demonstrated that different $\mathrm{N}-\mathrm{H} \cdots \mathrm{N}$ intermolecular hydrogen-bonding arrangements (quartet and ribbon) can be unambiguously identified in the spectra of the supramolecular guanosine structures. ${ }^{48}$ The intermolecular coupling constants in these structures have later been quantified by a ${ }^{15} \mathrm{~N}$ MAS spinecho experiment. ${ }^{46}$ J-coupling-based experiments, such as INADEQUATE, provide direct information on bonding pathways (including through hydrogen bonds). However, experiments which use dipolar (i.e. through space) couplings, either directly between two ${ }^{15} \mathrm{~N}$ nuclei ${ }^{49}$ or indirectly via proton-driven spin diffusion, ${ }^{50}$ can also be used to identify inter-residue $\mathrm{N}-\mathrm{H} \cdots \mathrm{N}$ hydrogen bonding e.g. in RNA.

Solid-state NMR can distinguish between polymorphs and is particularly suited for characterising subtle differences in crystal packing. For example, five polymorphs and one hydrate of 2-thiobarbituric acid have been characterised by $1 \mathrm{D}$ and 2D $\left({ }^{1} \mathrm{H},{ }^{13} \mathrm{C}\right.$, and $\left.{ }^{15} \mathrm{~N}\right)$ solid-state NMR spectroscopy. The polymorphs differ in the tautomeric form of the compound; an enol form, a keto form, or a 1:1 mixture of both are present in the crystals. The tautomeric form is easily recognised by ${ }^{13} \mathrm{C}$ CP-MAS spectroscopy, because the carbon chemical shift of C5 differs by $c a .40 \mathrm{ppm}$ (see Fig. 4). ${ }^{51,52}$ Complete assignments of ${ }^{1} \mathrm{H}$ and ${ }^{13} \mathrm{C}$ resonances were obtained by combining $1 \mathrm{D}$ and $2 \mathrm{D}$ (homo- and heteronuclear data). ${ }^{1} \mathrm{H}$ MAS NMR experiments provided information on hydrogen-bonded protons and their interaction strengths; the high ${ }^{1} \mathrm{H}$ chemical shift values (close to $15 \mathrm{ppm}$ ) in two polymorphs suggested the presence of strong interactions, which is consistent with short hydrogen bonds observed by X-ray crystallography. ${ }^{51}$

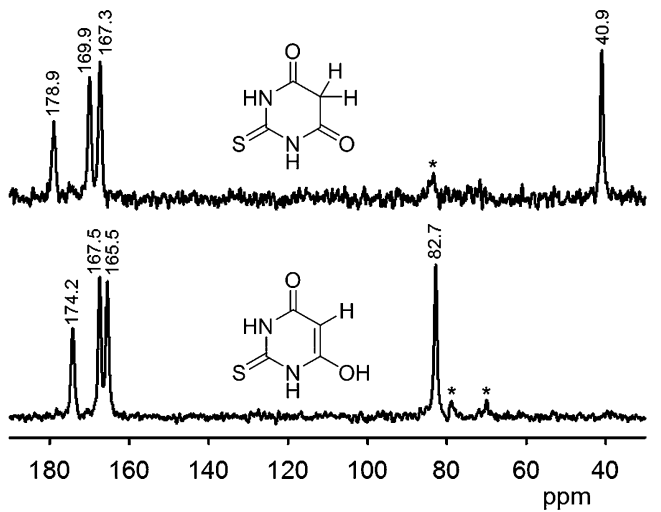

Fig. $4{ }^{13} \mathrm{C}$ CP-MAS spectra of two polymorphs of 2-thiobarbituric acid. Polymorph III (top) contains keto form and polymorph II (bottom) enol form of 2-thiobarbituric acid. The asterisks indicate spinning sidebands.

Co-crystals between a pharmaceutically active compound and a solid co-former are being widely investigated as an alternative to the use of drug salts for improving solid form properties (typically solubility). ${ }^{13} \mathrm{C}$ NMR can straightforwardly verify the formation of a co-crystal, which will have an NMR spectrum which is distinct from that of the sum of the individual components. For example, ${ }^{13} \mathrm{C}$ CP-MAS has been used to confirm co-crystal formation between acyclovir (an acyclic nucleoside antiviral drug) with both glutaric and fumaric acids. The carbon chemical shifts of acyclovir changed only slightly, which was rationalised in terms of the acyclovir molecule being involved in strong hydrogen bonding both in its pure and cocrystal forms. On the other hand, both glutaric and fumaric acid experience very different environments in the two cases, leading to changes in number of peaks due to changes of symmetry, and chemical shift changes of up to $5 \mathrm{ppm} .^{53}$

\section{Dynamics}

Nucleic acids are highly flexible molecules that undergo functionally important structural transitions in response to external stimuli. ${ }^{54}$ Sequence-specific DNA flexibility plays essential roles in a variety of cellular processes that are crucial for gene packaging, expression and regulation. ${ }^{55,56}$ For example, intrinsic sequencespecific DNA flexibility is believed to play an important function in directing adaptive changes in DNA conformation that occur following protein and ligand recognition. ${ }^{57,58}$ It has also been proposed that a dynamic component or flexibility of a lesion nucleotide plays a significant role in the biomolecular recognition process of DNA lesions by repair enzymes..$^{59,60}$ Similarly, many RNA functions are related to a multitude of functional dynamics. ${ }^{61}$

The dynamics of nucleic acids span a broad range of time scales from picoseconds, where fast vibrational and librational motions occur, up to seconds, where catalytic function and global refolding take place. X-ray crystallography and solution NMR have contributed high-resolution structures of nucleic acids, but neither technique is suitable for an investigation of dynamics over such a broad range. On the other hand, solidstate NMR can probe motions with correlation times ranging 
over several orders of magnitudes. ${ }^{\mathbf{6 , 6 2}}$ A particular advantage of working in the solid state is that it is unnecessary to deconvolute the effects of overall molecular motions. Pre-1991 solidstate NMR studies of DNA structure and dynamics have been reviewed by Alam and Drobny. ${ }^{9}$ This review also describes dynamic and motional processes in DNA and basic principles of NMR determination of DNA dynamics. Solid-state NMR may also help the interpretation of solution-state relaxation times by providing experimental chemical shift anisotropies. For example, the ${ }^{31} \mathrm{P}$ chemical shift anisotropy of a 20 mer RNA oligonucleotide under various salt and hydration conditions has been measured in order to interpret ${ }^{31} \mathrm{P}$ relaxation data in solution. ${ }^{63}$ The principal components of ${ }^{13} \mathrm{C}$ and ${ }^{15} \mathrm{~N}$ chemicalshift tensors in solid 3-, 7-, and 9-benzyladenine isomers have been determined and the influence of the substitution on the magnitude and orientation of the tensors has been discussed. ${ }^{64}$

Several isotopes can be utilised as probes for measuring dynamics in the solid state. One of the most useful isotopes is deuterium, because the solid-state NMR line shape and relaxation of deuterium spins are essentially dominated by a single mechanism - the interaction of the nuclear quadrupole moment with local electric field gradients. Using systematic isotopic labelling schemes, the local dynamics of the base, sugar, and backbone moieties of individual nucleotides within a sequence can be investigated with deuterium solid-state NMR experiments. A combination of deuterium line shape and relaxation data probes a wide range of motions from nanosecond time-scale dynamics (probed by relaxation measurements) to micro/millisecond time scales (from line shape measurements). ${ }^{65}$

For example, the internal motions of the nucleoside 2 -deoxythymidine in the solid state have been investigated by deuterium SS-NMR. The base position was found to be essentially rigid, even at elevated temperatures. On the other hand, $T_{1}$ measurements on $2^{\prime}, 2^{\prime \prime}$-dideuterothymidine indicated the presence of two kinds of motion: (1) small-amplitude librations on the nanosecond time scale and (2) large amplitude jumping motions on the millisecond to microsecond time scale, which were hypothesised to be $2^{\prime}$-endo- $3^{\prime}$-endo interconversion. ${ }^{\mathbf{6}}$ Similarly two kinds of motion have been observed in a hydrated, non-crystalline sample of D-ribose selectively ${ }^{2} \mathrm{H}$-labelled at the $2^{\prime}$ position. $^{67}$

Methylation of nucleotide bases is important for many biological processes. The $H$ haI system is a restriction-modification system consisting of a methyltransferase and endonuclease, which together act as a defense mechanism in prokaryotic systems, protecting the cell from invasive DNA. Deuterium SS-NMR has been used to understand and quantify the extent to which dynamics may assist proteins to recognise methylation sites distributed within DNA double helix, and to quantify the degree to which methylation perturbs the local dynamics of DNA (see Fig. 5 for an example of deuterium line shape analysis). ${ }^{65,68}$ The spectra obtained from DNAs selectively deuterated on the furanose ring within the GCGC moiety, recognised by the HhaI methyltransferase, indicated that all of these positions were structurally flexible. The furanose ring within the deoxycytidine that is the methylation target displayed the largest amplitude motion and $c a$. 10 times higher jump rates obtained by fitting the deuterium line shapes, whereas the furanose rings of nucleotides more remote from the methylation site had less mobile furanose rings. Furthermore, deuterium solid-state NMR revealed that methylation of the cytidine base reduces the amplitudes of motions of the phosphate - sugar backbone $^{\mathbf{6 8 , 6 9}}$ and changes the direction of the motions, ${ }^{70}$ even
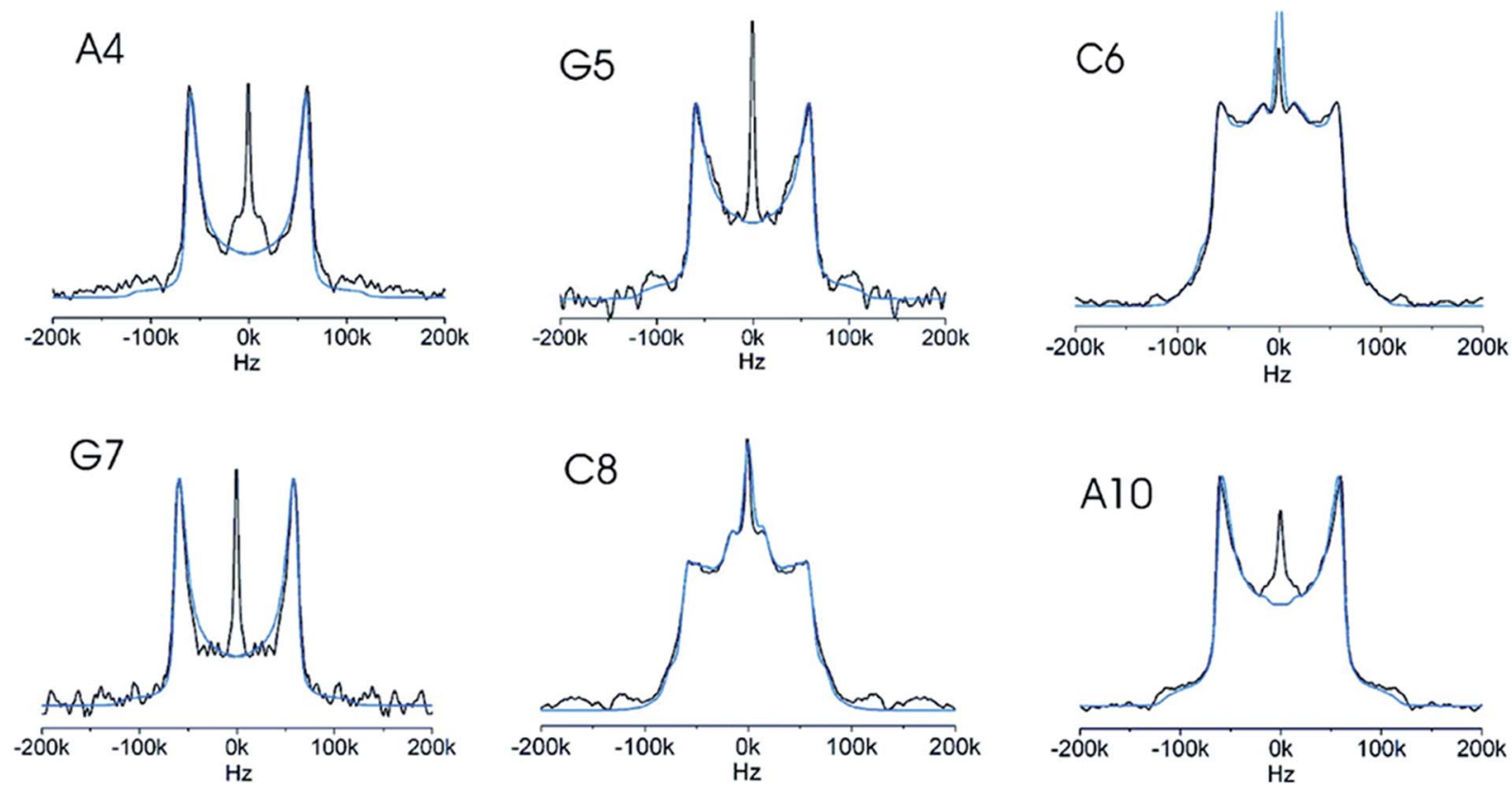

Fig. 5 Six experimental deuterium line shapes (black) for individual selectively labelled sites in a DNA dodecamer with the simulation (blue) of each overlaid. The differences between the line shapes are caused by different local dynamics of the individual sites. Reprinted with permission from (ref. 65) Copyright 2008 American Chemical Society. 
though the crystal structures displayed only small perturbations from unmethylated DNA. The deuterium solid-state NMR data were later compared with ${ }^{13} \mathrm{C}$ solution relaxation measurements ${ }^{71}$ and with variable temperature solution ${ }^{31} \mathrm{P} \mathrm{NMR}^{72}$ and it was concluded that the local internal motions of the studied DNA oligomer in solution and in the hydrated solid state were virtually the same. On the basis of these results, it was hypothesized that local DNA dynamics promotes methylation by lowering energetic barriers for the conformational changes required for HhaI binding.

In a similar study, solid-state ${ }^{2} \mathrm{H}$ line shape and inversion recovery data were collected for six DNA samples containing deuterons at the $\mathrm{H} 2$ " positions of various residues of a DNA dodecamer. The DNA was hydrated to 11-13 waters per nucleotide by vapour diffusion in a humidity chamber containing saturated salts in ${ }^{2} \mathrm{H}$-depleted water, to reach conditions where motions in the solid are very close to those observed in solution $^{73}$ and to establish that the line shapes do not differ simply as a result of differential hydration. Remarkable variations in line shape and longitudinal relaxation times $\left(T_{1 \mathrm{z}}\right)$ were observed between residues framing the methylation site and their neighbours. The residues close to the methylation site had shorter $T_{1 \mathrm{Z}}$ values of $20-30 \mathrm{~ms}$ and a noticeable modulation of the line shape, suggesting considerable motional averaging. Nearby residues were not nearly as flexible, as demonstrated by the line shapes and significantly larger $T_{1 \mathrm{z}}(59-82 \mathrm{~ms})$. It was established that all $\mathrm{H}_{2}{ }^{\prime \prime}$ nuclei experienced small amplitude librations $\left(10^{\circ}\right)$ of the $\mathrm{C}-\mathrm{D}$ bond at frequencies faster than the quadrupolar interaction ( $174 \mathrm{kHz}$ ), and, in addition, $\mathrm{H}_{2}$ " nuclei on the nucleotides close to the methylation site experienced large amplitude motions $\left(36^{\circ}\right)$ at similar frequencies. These effects are specific for the methylation target DNA sequence as other DNAs revealed no significant variation in $T_{1 \mathrm{Z}}$ or line shapes between individual residues. ${ }^{74}$

On the other hand, no significant differences in the local dynamics of the furanose ring within a uracil : adenine (U : A) base pair and a normal thymine : adenine $(\mathrm{T}: \mathrm{A})$ base pair have been revealed by deuterium solid-state NMR. The relaxation times were identical within the experimental error and the solid lineshapes were essentially indistinguishable. Therefore, $\mathrm{U}: \mathrm{A}$ base pair furanose rings appeared to have identical dynamic properties as a normal $\mathrm{T}$ : A base pair, and the local dynamics of the furanose ring are unlikely to be the sole arbiter for uracil recognition and specificity in $\mathrm{U}$ : A base pairs. ${ }^{75}$

A solid-state deuterium NMR study of localised mobility at the C9pG10 step, the EcoRI restriction endonuclease target, in the DNA Dickerson dodecamer has been described both in crystalline and amorphous state. ${ }^{76,77}$ The furanose ring and helix backbone of dC9 display large amplitudes of motion on the $0.1 \mu$ s time scale, which contrasts with much smaller local dynamics in other nucleotides (dA5, dA6, dT7, and dT8) of the same dodecamer derived by earlier ${ }^{2} \mathrm{H}$ NMR studies. ${ }^{78,79}$ The large amplitude motions occur only close to the site where the EcoRI restriction endonuclease binds and cleaves.

NMR interactions can be significantly influenced by fast molecular motions, such as vibrations. A theoretical study that combined DFT molecular dynamics simulations of a set of amino acids and nucleic acid bases with calculations of NMR parameters revealed the impact of vibrational motions on isotropic chemical shifts, chemical shift anisotropies (CSAs) and quadrupolar interactions. Re-orientation of the NMR tensors by molecular motion reduces the magnitudes of the NMR anisotropies, and inclusion of molecular dynamics significantly improved the agreement between calculated quadrupolar couplings and experimental values. ${ }^{80}$

NMR experiments together with molecular dynamics simulations and NMR calculations have been used to investigate mobility of water molecules and sodium ions in solid hydrates of two nucleotides. The structure of guanosine monophosphate system was found to be relatively rigid, with a well-ordered solvation shell of the nucleotide, while the water molecules in the uridine monophosphate system were shown to be remarkably mobile even at $-80^{\circ} \mathrm{C}$. The disorder of water molecules was observed in the ${ }^{13} \mathrm{C},{ }^{31} \mathrm{P}$, and ${ }^{23} \mathrm{Na}$ solid-state NMR experiments as multiple signals for equivalent sites of the nucleotide corresponding to different local arrangements of the solvation shell. Deuterium NMR spectra of the samples recrystallized from $\mathrm{D}_{2} \mathrm{O}$ and molecular dynamics simulations also confirmed differences in water mobility between the two systems. The disordered solvation shell in UMP was proposed to be a good model for solvated nucleotides in general, with fast reorientation of water molecules and fluctuations in the hydrogen-bond network. ${ }^{81}$

\section{Interactions with metal ions}

Because (oligo)nucleotides are polyanions, their structure and biological function depends strongly on their association with metal ions. Metal ions are involved in almost every aspect of nucleic acid chemistry, ranging from neutralization of the anionic nucleic acids ${ }^{\mathbf{8 2}}$ through specific stabilization of threedimensional structures of nucleic acid molecules, up to their effect as cofactors in RNA-mediated catalysis. ${ }^{83}$ However, the dynamic non-covalent nature of these interactions has hampered the development of accurate and quantitative descriptions. ${ }^{\mathbf{8 4}}$ Direct detection of light alkali metal ions by diffraction techniques is challenging, especially for sodium cations, because their X-ray scattering contributions are virtually identical to those of water, and $\mathrm{Na}^{+} \cdots \mathrm{O}$ distances are only slightly shorter than strong hydrogen bonds between well-ordered water molecules. ${ }^{\mathbf{8 5}}$ This often renders it impossible to identify $\mathrm{Na}^{+}$ions, even with state-of-the-art diffraction techniques.

Most of the metals that bind to nucleic acids are diamagnetic and possess significantly abundant isotopes that are NMRactive, making them potential targets for NMR. Unfortunately, the majority of these biologically significant isotopes also involve half-integer quadrupolar nuclei that provide limited information by solution-state NMR experiments due to the efficient quadrupolar relaxation that significantly broadens the NMR spectral lines. Moreover exchange of metals between bound sites and bulk solution is fast on the NMR timescale. These problems can be circumvented by carrying out the NMR experiments in the solid state, where the chemical exchange is stopped (or significantly reduced) and relaxation broadening quenched by the absence of rapid reorientations. ${ }^{86}$ 
Solid-state NMR has been frequently used for the characterisation of metal-ion interactions with nucleic acid components. For example, natural abundance ${ }^{15} \mathrm{~N}$ solid-state NMR spectra of complexes formed between $\mathrm{Na}^{+}, \mathrm{Ba}^{2+}$, and $\mathrm{Cd}^{2+}$ and guanosine- $5^{\prime}$-monophosphate and inosine- $5^{\prime}$-monophosphate demonstrated the great sensitivity of ${ }^{15} \mathrm{~N}$ shieldings to metal ion coordination. It was also shown that changes in the ${ }^{15} \mathrm{~N}$ chemical shift upon ion binding could be correlated with the strength and directionality of metal to nitrogen coordination. ${ }^{87}$

${ }^{23} \mathrm{Na}$ NMR has been applied in several studies of the sodium salts of nucleotides. Usually, $1 \mathrm{D}^{23} \mathrm{Na}$ MAS spectra do not exhibit resolved features from which information on the number of sodium sites and the associated NMR parameters can be readily extracted. In contrast, $2 \mathrm{D}{ }^{23} \mathrm{Na}$ multiple-quantum MAS (MQMAS) spectra usually display clearly distinct spectral regions corresponding to distinct sodium sites in the crystal lattice (see Fig. 6). From individual spectral cross-sections, it is possible to obtain three ${ }^{23} \mathrm{Na} \mathrm{NMR}$ parameters: the isotropic chemical shift $\delta_{\text {iso }}$, quadrupolar coupling $C_{\mathrm{Q}}$ and quadrupolar asymmetry $\eta_{\mathrm{Q}}$. In some cases, the assignment of the NMR parameters to individual sites has been made on the basis of a simple correlation between $C_{\mathrm{Q}}$ and the local ion-binding geometry. ${ }^{\mathbf{8 8 , 8 9}} \mathrm{A}$ partial assignment of the four non-equivalent sodium sites of $\mathrm{Na}_{2} \mathrm{ATP}$ was accomplished by incorporating ${ }^{31} \mathrm{P}-{ }^{23} \mathrm{Na}$ rotational echo double resonance (REDOR), variable temperature and relaxation methodologies onto the basic MQMAS high-resolution experiment. ${ }^{90}$ In the same paper, ${ }^{23} \mathrm{Na}$ spin-lattice relaxation times were also determined and related to local mobility around the individual sodium sites. Highresolution $1 \mathrm{D}$ and $2 \mathrm{D}{ }^{23} \mathrm{Na}$ NMR spectra of deoxyguanosine-5'monophosphate have also been obtained with the doublerotation (DOR) technique. ${ }^{\mathbf{9 1}}$

A solid-state ${ }^{23} \mathrm{Na}$ NMR study of monovalent cation $\left(\mathrm{Li}^{+}, \mathrm{Na}^{+}\right.$, $\mathrm{K}^{+}, \mathrm{Rb}^{+}, \mathrm{Cs}^{+}$, and $\mathrm{NH}_{4}^{+}$) binding to double-stranded calf thymus DNA at low relative humidity has been reported. Results from ${ }^{23} \mathrm{Na}-{ }^{31} \mathrm{P}$ REDOR experiment established that monovalent cations are directly bound to the phosphate groups of DNA and are partially dehydrated under these conditions. Quantitative thermodynamic parameters concerning the cation-binding affinity for the phosphate group were obtained by ${ }^{23} \mathrm{Na} \mathrm{NMR}$ titration experiments. These binding affinities were shown to be significantly different from those observed for the DNA in solution. ${ }^{92}$

Although magnesium is essential for the proper physiological folding of polynucleotides, direct NMR studies on this ion are complicated by its unfavourable nuclear properties (low natural abundance of ${ }^{25} \mathrm{Mg}$, low magnetogyric ratio, large quadrupolar moment). One possible magnesium analogue is $\left[\mathrm{Co}\left(\mathrm{NH}_{3}\right)_{6}\right]^{3+}$, which binds to nucleic acids and is of similar size and shape as hexaaquamagnesium. The ${ }^{59} \mathrm{Co}$ nuclide is a $100 \%$ naturally abundant isotope with relatively high magnetogyric ratio and moderate quadrupole moment. It has been demonstrated that ${ }^{59}$ Co MAS experiments on relatively small amount of tRNA can distinguish resonances corresponding to different metal binding environments. These characterisations were assisted by studies on model compounds and by ${ }^{31} \mathrm{P}-{ }^{59} \mathrm{Co}$ recoupling experiments. ${ }^{86}$

G-quadruplexes are DNA and RNA structural motifs composed of stacked G-quartets in which four guanine residues form a planar arrangement (Fig. 7). Because of their relevance to biological processes, such as DNA replication and transcription, these uncanonical structures are considered to be novel therapeutic targets and have also been identified as promising building blocks for DNA-based nanomaterials and nanodevices. ${ }^{93-95}$

Alkali metal ions such as $\mathrm{Na}^{+}$and $\mathrm{K}^{+}$are known to play important roles in the formation, stability, and structural polymorphism of G-quadruplexes. Solution NMR has been used for studying alkali metal ion binding to G-quadruplexes. Although it is generally difficult to obtain site-specific information, with exceptions where spin-1/2 nuclear probes of ${ }^{205} \mathrm{Tl}^{+}$ and ${ }^{15} \mathrm{NH}_{4}{ }^{+}$were used (see, for example, ref. 96-98), it has been recently shown that insight into the binding of sodium and potassium ions can also be obtained by NMR in solution. ${ }^{99}$ Solid-state NMR has emerged as a method for directly detecting alkali metal ions in these and related systems. Recently, solidstate NMR techniques have been successfully developed for the determination of cation coordination within G-quartet. Wu's group has studied the solid-state ${ }^{23} \mathrm{Na},{ }^{39} \mathrm{~K}$, and ${ }^{87} \mathrm{Rb}$ NMR of guanosine complexes. For example, solid-state ${ }^{23} \mathrm{Na}$ NMR has been used to determine the mode of $\mathrm{Na}^{+}$binding to an
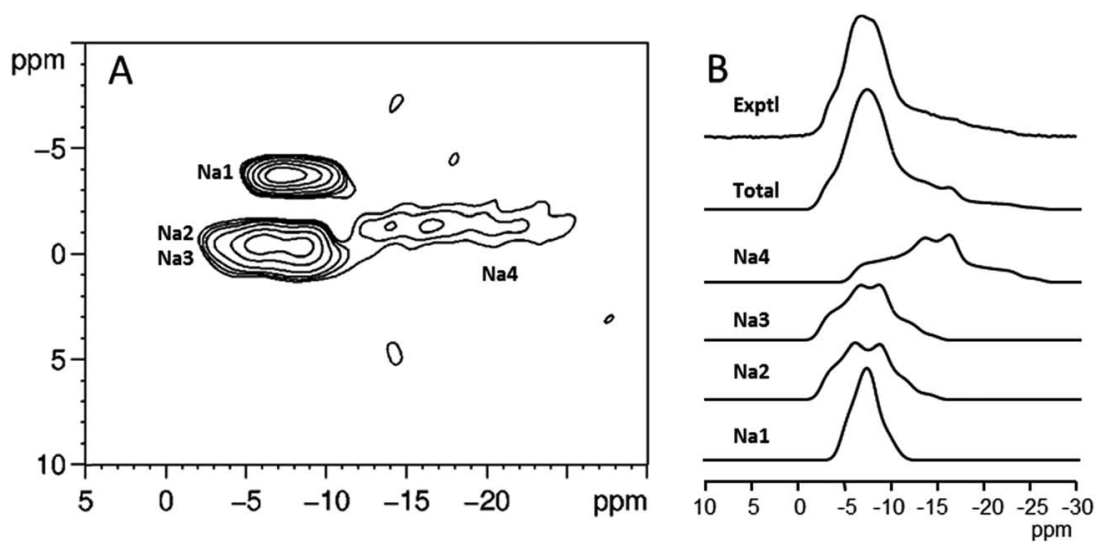

Fig. 6 (A) ${ }^{23} \mathrm{Na}$ MQMAS spectra of the disodium salt of guanosine-5'-monophosphate heptahydrate. (B) Individual cross-sections of the MQMAS spectrum, their sum, and the experimental $1 D^{23} \mathrm{Na}$ MAS spectrum. Figure adapted from results originally published in (ref. 89 ). 


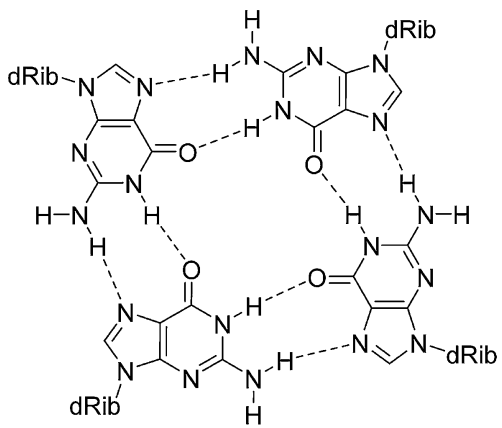

Fig. 7 Diagram illustrating the cyclic hydrogen bonding in a G-quartet. The monovalent cation, which resides in or out of the guanine plane, is omitted.

Oxytricha nova telomeric DNA repeat. Using a 2D MQMAS ${ }^{23} \mathrm{Na}$ experiment, three sodium cations residing inside the quadruplex channel were observed. Each of these sodium cations was sandwiched between two G-quartets. ${ }^{100}$ The utility of $2 \mathrm{D}$ MQMAS ${ }^{23} \mathrm{Na}$ experiment in obtaining accurate site-specific information about ion binding in G-quadruplexes has also been confirmed in other studies. ${ }^{101-103}$

The relative affinity of monovalent cations for a stacking G-quartet structure was studied by solid-state NMR. Two major types of cations were found to be bound to the structure: one at the surface and the other within the channel cavity between two G-quartets. On the basis of solid-state ${ }^{23} \mathrm{Na}$ results from a series of ion titration experiments, quantitative thermodynamic parameters concerning the relative cation binding affinity for each of the two major binding sites have been obtained. ${ }^{104}{ }^{23} \mathrm{Na}$ NMR and quantum chemical calculations have also been used to determine the coordination of the sodium ion in a calix[4]arene-guanosine conjugate dimer, which was shown to form a single G-quartet at the centre of the structure with pentacoordinated sodium ion. ${ }^{105}{ }^{23} \mathrm{Na}$ spin-echo experiments have been used to selectively suppress the phosphate-bound $\mathrm{Na}^{+}$ions in a solid G-quadruplex, because they have shorter decoherence times than the G-quartet-bound sodium atoms. ${ }^{99}$

The presence of $\mathrm{K}^{+}$ions in cells is believed to be crucial for the stability of telomeric G-quadruplex structures. The rather weak association between $\mathrm{K}^{+}$ions and biological structures together with the low gyromagnetic ratio of ${ }^{39} \mathrm{~K}$ (spin 3/2) renders solution ${ }^{39} \mathrm{~K}$ NMR spectroscopy of limited utility. However, solid-state NMR detection of $\mathrm{K}^{+}$ions bound to G-quadruplex structures has been shown to provide an unambiguous signature of potassium ions bound to G-quadruplex. ${ }^{106}$ It has been also proposed that ${ }^{87} \mathrm{Rb}$ can be used as a surrogate of potassium for detecting $\mathrm{K}^{+}$binding by solid-state NMR, because ${ }^{87} \mathrm{Rb}$ has a much higher NMR sensitivity than ${ }^{39} \mathrm{~K}$, but a similar radius. ${ }^{107}$

\section{Conclusions}

Despite their biological importance, many important issues related to the structure, dynamics and function of nucleic acids are not well understood. In this review, we have described recent applications of solid-state NMR and NMR crystallography to the study of nucleic acid components, focussing on applications where SS-NMR provides structural or dynamic information that is not accessible by other methods. Recent advances in experimental SS-NMR methods and DFT computations have opened new ways for studying nucleic acid systems. Limited motion in solids allows direct characterisation of individual conformations and intra- and intermolecular interactions. Furthermore, the local dynamics and interactions with the solvation shell and metal ions in solid hydrates are close to the hydration environment in solution, without the complication of overall molecular motion. Moreover, progress in the calculation of NMR parameters of solids enables NMR observables to be linked with structural models, greatly helping the interpretation of the experimental data. Solid-state NMR and NMR crystallography have thus become viable methods of determining the structure and local dynamics of nucleic acids and their components.

\section{Acknowledgements}

This work was supported by the Czech Science Foundation (grant no. 13-24880S). The authors thank Prof. Gang Wu for providing the artwork for Fig. 6 .

\section{References}

1 G. M. Blackburn, M. J. Gait, D. Loakes and D. M. Williams, Nucleic Acids in Chemistry and Biology: RSC, The Royal Society of Chemistry, Cambridge, 2006.

2 C. Simons, Q. P. Wu and T. T. Htar, Curr. Top. Med. Chem., 2005, 5, 1191-1203.

3 E. De Clercq and A. Holý, Nat. Rev. Drug Discovery, 2005, 4, 928-940.

4 R. A. Santos, P. Tang and G. S. Harbison, Biochemistry, 1989, 28, 9372-9378.

5 NMR Crystallography, ed. R. K. Harris, R. E. Wasylishen and M. J. Duer, John Wiley \& Sons, Chichester, 2009.

6 D. C. Apperley, R. K. Harris and P. Hodgkinson, Solid-State NMR: Basic Principles \& Practice, Momentum Press, New York, 2012.

7 M. J. Duer, Introduction to Solid-State NMR Spectroscopy, Blackwell Publishing Ltd, Oxford, 2004.

8 A. Ramamoorthy, NMR Spectroscopy of Biological Solids, CRC Press, Boca Raton, 2005.

9 T. M. Alam and G. P. Drobny, Chem. Rev., 1991, 91, 15451590.

10 T. Gullion and J. Schaefer, Adv. Magn. Reson., 1989, 13, 5783.

11 M. Kaupp, M. Bühl and V. G. Malkin, Calculation of NMR and EPR Parameters, Wiley-VCH, Weinheim, 2004.

12 C. Bonhomme, C. Gervais, F. Babonneau, C. Coelho, F. Pourpoint, T. Azais, S. E. Ashbrook, J. M. Griffin, J. R. Yates, F. Mauri and C. J. Pickard, Chem. Rev., 2012, 112, 5733-5779.

13 C. J. Pickard and F. Mauri, Phys. Rev. B: Condens. Matter Mater. Phys., 2001, 6324, 245101. 
14 R. K. Harris, P. Hodgkinson, C. J. Pickard, J. R. Yates and V. Zorin, Magn. Reson. Chem., 2007, 45, S174-S186.

15 M. Dračínský, P. Jansa, K. Ahonen and M. Buděšínský, Eur. J. Org. Chem., 2011, 1544-1551.

16 X. P. Xu, W. L. A. K. Chiu and S. C. F. Au-Yeung, J. Am. Chem. Soc., 1998, 120, 4230-4231.

17 J. M. Fonville, M. Swart, Z. Vokáčová, V. Sychrovský, J. E. Šponer, J. Šponer, C. W. Hilbers, F. M. Bickelhaupt and S. S. Wijmenga, Chem.-Eur. J., 2012, 18, 12372-12387.

18 M. Ebrahimi, P. Rossi, C. Rogers and G. S. Harbison, J. Magn. Reson., 2001, 150, 1-9.

19 I. V. Sergeyev, L. A. Day, A. Goldbourt and A. E. McDermott, J. Am. Chem. Soc., 2011, 133, 20208-20217.

20 S. R. LaPlante, E. A. Boudreau, N. Zanatta, G. C. Levy, P. N. Borer, J. Ashcroft and D. Cowburn, Biochemistry, 1988, 27, 7902-7909.

21 L. van Dam and M. H. Levitt, J. Mol. Biol., 2000, 304, 541560.

22 B. Heddi, N. Foloppe, N. Bouchemal, E. Hantz and B. Hartmann, J. Am. Chem. Soc., 2006, 128, 9170-9177.

23 J. Přecechtělová, M. L. Munzarová, J. Vaara, J. Novotný, M. Dračínský and V. Sklenář, J. Chem. Theory Comput., 2013, 9, 1641-1656.

24 L. van Dam, N. Ouwerkerk, A. Brinkmann, J. Raap and M. H. Levitt, Biophys. J., 2002, 83, 2835-2844.

25 S. G. Patching, R. Edwards and D. A. Middleton, J. Magn. Reson., 2009, 199, 242-246.

26 D. R. Studelska, C. A. Klug, D. D. Beusen, L. M. McDowell and J. Schaefer, J. Am. Chem. Soc., 1996, 118, 5476-5477.

27 E. A. Louie, P. Chirakul, V. Raghunathan, S. T. Sigurdsson and G. P. Drobny, J. Magn. Reson., 2006, 178, 11-24.

28 G. L. Olsen, E. A. Louie, G. P. Drobny and S. T. Sigurdsson, Nucleic Acids Res., 2003, 31, 5084-5089.

29 D. A. Middleton, E. Hughes and M. Esmann, Angew. Chem., Int. Ed., 2011, 50, 7041-7044.

30 D. A. Middleton, E. Hughes, N. U. Fedosova and M. Esmann, ChemBioChem, 2009, 10, 1789-1792.

31 P. M. Macdonald, M. J. Damha, K. Ganeshan, R. Braich and S. V. Zabarylo, Nucleic Acids Res., 1996, 24, 2868-2876.

32 R. A. Fry, K. D. Kwon, S. Komarneni, J. D. Kubicki and K. T. Mueller, Langmuir, 2006, 22, 9281-9286.

33 N. M. Luscombe, R. A. Laskowski and J. M. Thornton, Nucleic Acids Res., 2001, 29, 2860-2874.

34 E. M. B. Janke, H. H. Limbach and K. Weisz, J. Am. Chem. Soc., 2004, 126, 2135-2141.

35 M. Barfield, A. J. Dingley, J. Feigon and S. Grzesiek, J. Am. Chem. Soc., 2001, 123, 4014-4022.

36 E. Pauwels, D. Claeys, J. C. Martins, M. Waroquier, G. Bifulco, V. Van Speybroeck and A. Madder, RSC Adv., 2013, 3, 3925-3938.

37 A. L. Webber, S. Masiero, S. Pieraccini, J. C. Burey, A. S. Tatton, D. Iuga, T. N. Pham, G. P. Spada and S. P. Brown, J. Am. Chem. Soc., 2011, 133, 19777-19795.

38 G. Arrachart, C. Carcel, J. J. E. Moreau, G. Hartmeyer, B. Alonso, D. Massiot, G. Creff, J. L. Bantignies, P. Dieudonne, M. W. C. Man, G. Althoff, F. Babonneau and C. Bonhomme, J. Mater. Chem., 2008, 18, 392-399.
39 A. C. Uldry, J. M. Griffin, J. R. Yates, M. Perez-Torralba, M. D. S. Maria, A. L. Webber, M. L. L. Beaumont, A. Samoson, R. M. Claramunt, C. J. Pickard and S. P. Brown, J. Am. Chem. Soc., 2008, 130, 945-954.

40 S. K. Amini, H. Shaghaghi, A. D. Bain, A. Chabok and M. Tafazzoli, Solid State Nucl. Magn. Reson., 2010, 37, 13-20. 41 G. Wu, S. Dong, R. Ida and N. Reen, J. Am. Chem. Soc., 2002, 124, 1768-1777.

42 G. Wu, S. Dong and R. Ida, Chem. Commun., 2001, 891-892. 43 G. Wu and S. Dong, J. Am. Chem. Soc., 2001, 123, 9119-9125. 44 I. C. M. Kwan, X. Mo and G. Wu, J. Am. Chem. Soc., 2007, 129, 2398-2407.

45 S. A. Joyce, J. R. Yates, C. J. Pickard and S. P. Brown, J. Am. Chem. Soc., 2008, 130, 12663-12670.

46 T. N. Pham, J. M. Griffin, S. Masiero, S. Lena, G. Gottarelli, P. Hodgkinson, C. Fillip and S. P. Brown, Phys. Chem. Chem. Phys., 2007, 9, 3416-3423.

47 A. J. Dingley and S. Grzesiek, J. Am. Chem. Soc., 1998, 120, 8293-8297.

48 T. N. Pham, S. Masiero, G. Gottarello and S. P. Brown, J. Am. Chem. Soc., 2005, 127, 16018-16019.

49 J. Leppert, C. R. Urbinati, S. Hafner, O. Ohlenschlager, M. S. Swanson, M. Gorlach and R. Ramachandran, Nucleic Acids Res., 2004, 32, 1177-1183.

50 K. Riedel, J. Leppert, O. Ohlenschlager, M. Gorlach and R. Ramachandran, J. Biomol. NMR, 2005, 31, 331-336.

51 M. R. Chierotti, L. Ferrero, N. Garino, R. Gobetto, L. Pellegrino, D. Braga, F. Grepioni and L. Maini, Chem.Eur. J., 2010, 16, 4347-4358.

52 M. Dračínský, E. Procházková, J. Kessler, J. Šebestík, P. Matějka and P. Bouř, J. Phys. Chem. B, 2013, 117, 72977307.

53 G. Bruni, M. Maietta, L. Maggi, P. Mustarelli, C. Ferrara, V. Berbenni, C. Milanese, A. Girella and A. Marini, J. Pharm. Sci., 2013, 102, 4079-4086.

54 E. N. Nikolova and H. M. Al-Hashimi, J. Biomol. NMR, 2009, 45, 9-16.

55 H. G. Garcia, P. Grayson, L. Han, M. Inamdar, J. Kondev, P. C. Nelson, R. Phillips, J. Widom and P. A. Wiggins, Biopolymers, 2007, 85, 115-130.

56 F. Gimenes, K. I. Takeda, A. Fiorini, F. S. Gouveia and M. A. Fernandez, Genet. Mol. Res., 2008, 7, 549-558.

57 Z. Shajani and G. Varani, Biochemistry, 2008, 47, 7617-7625. 58 S. Fujii, H. Kono, S. Takenaka, N. Go and A. Sarai, Nucleic Acids Res., 2007, 35, 6063-6074.

59 J. T. Stivers, Prog. Nucleic Acid Res. Mol. Biol., 2004, 77, 3765.

60 W. Yang, Cell Res., 2008, 18, 184-197.

61 H. M. Al-Hashimi and N. G. Walter, Curr. Opin. Struct. Biol., 2008, 18, 321-329.

62 R. Tycko, Nuclear Magnetic Resonance Probes of Molecular Dynamics, Kluwer Academic Publishers, Dordecht, 1994.

63 J. Rinnenthal, C. Richter, S. Nozinovic, B. Furtig, J. J. Lopez, C. Glaubitz and H. Schwalbe, J. Biomol. NMR, 2009, 45, 143155.

64 K. Maliňáková, L. Novosadová, M. Pipíška and R. Marek, ChemPhysChem, 2011, 12, 379-388. 
65 G. A. Meints, P. A. Miller, K. Pederson, Z. Shajani and G. Drobny, J. Am. Chem. Soc., 2008, 130, 7305-7314.

66 Y. Hiyama, S. Roy, J. S. Cohen and D. A. Torchia, J. Am. Chem. Soc., 1989, 111, 8609-8613.

67 A. C. LiWang, D. E. McCready, G. P. Drobny, B. R. Reid and M. A. Kennedy, J. Biomol. NMR, 2003, 26, 249-257.

68 G. A. Meints and G. P. Drobny, Biochemistry, 2001, 40, 12436-12443.

69 K. B. Geahigan, G. A. Meints, M. E. Hatcher, J. Orban and G. P. Drobny, Biochemistry, 2000, 39, 4939-4946.

70 K. Pederson, G. A. Meints, Z. Shajani, P. A. Miller and G. P. Drobny, J. Am. Chem. Soc., 2008, 130, 9072-9079.

71 D. Echodu, G. Goobes, Z. Shajani, K. Pederson, G. Meints, G. Varani and G. Drobny, J. Phys. Chem. B, 2008, 112, 13934-13944.

72 Y. Tian, M. Kayatta, K. Shultis, A. Gonzalez, L. J. Mueller and M. E. Hatcher, J. Phys. Chem. B, 2009, 113, 2596-2603.

73 J. M. Schurr, B. S. Fujimoto, R. Diaz and B. H. Robinson, J. Magn. Reson., 1999, 140, 404-431.

74 P. A. Miller, Z. Shajani, G. A. Meints, D. Caplow, G. Goobes, G. Varani and G. P. Drobny, J. Am. Chem. Soc., 2006, 128, 15970-15971.

75 M. N. Kinde-Carson, C. Ferguson, N. A. Oyler, G. S. Harbison and G. A. Meints, J. Phys. Chem. B, 2010, 114, 3285-3293.

76 M. E. Hatcher, I. LeTrong, R. Stenkamp and G. P. Drobny, J. Am. Chem. Soc., 2001, 123, 8874-8875.

77 M. E. Hatcher, D. L. Mattiello, G. A. Meints, J. Orban and G. P. Drobny, J. Am. Chem. Soc., 1998, 120, 9850-9862.

78 W. C. Huang, J. Orban, A. Kintanar, B. R. Reid and G. P. Drobny, J. Am. Chem. Soc., 1990, 112, 9059-9068.

79 T. M. Alam, J. Orban and G. P. Drobny, Biochemistry, 1991, 30, 9229-9237.

80 M. Dračínský and P. Hodgkinson, CrystEngComm, 2013, 15, 8705-8712.

81 M. Dračínský, M. Šála and P. Hodgkinson, CrystEngComm, 2014, 16, 6756-6764.

82 J. J. Howard, G. C. Lynch and B. M. Pettitt, J. Phys. Chem. B, 2011, 115, 547-556.

83 J. Müller, Metallomics, 2010, 2, 318-327.

84 Nucleic Acid-Metal Ion Interactions, ed. N. V. Hud, Royal Society of Chemistry, Cambridge, 2009.

85 V. Tereshko, C. J. Wilds, G. Minasov, T. P. Prakash, M. A. Maier, A. Howard, Z. Wawrzak, M. Manoharan and M. Egli, Nucleic Acids Res., 2001, 29, 1208-1215.
86 C. V. Grant, V. Frydman, J. S. Harwood and L. Frydman, J. Am. Chem. Soc., 2002, 124, 4458-4462.

87 K. Barbarossou, A. E. Aliev, I. P. Gerothanassis, J. Anastassopoulou and T. Theophanides, Inorg. Chem., 2001, 40, 3626-3628.

88 G. Wu and A. Wong, in NMR Spectroscopy of Biological Solids, ed. A. Ramamoorthy, CRC Press, Boca Raton, 2006.

89 G. Wu and J. F. Zhu, Prog. Nucl. Magn. Reson. Spectrosc., 2012, 61, 1-70.

90 C. V. Grant, D. McElheny, V. Frydman and L. Frydman, Magn. Reson. Chem., 2006, 44, 366-374.

91 F. A. Perras, I. Korobkov and D. L. Bryce, Phys. Chem. Chem. Phys., 2012, 14, 4677-4681.

92 A. Wong, Z. M. Yan, Y. N. Huang and G. Wu, Magn. Reson. Chem., 2008, 46, 308-315.

93 J. T. Davis, Angew. Chem., Int. Ed., 2004, 43, 668-698.

94 D. S. Liu, E. J. Cheng and Z. Q. Yang, NPG Asia Mater., 2011, 3, 109-114.

95 R. Rodriguez, K. M. Miller, J. V. Forment, C. R. Bradshaw, M. Nikan, S. Britton, T. Oelschlaegel, B. Xhemalce, S. Balasubramanian and S. P. Jackson, Nat. Chem. Biol., 2012, 8, 301-310.

96 M. Trajkovski and J. Plavec, J. Phys. Chem. C, 2012, 116, 23821-23825.

97 M. L. Gill, S. A. Strobel and J. P. Loria, J. Am. Chem. Soc., 2005, 127, 16723-16732.

98 P. Sket, A. Virgilio, V. Esposito, A. Galeone and J. Plavec, Nucleic Acids Res., 2012, 40, 11047-11057.

99 R. Ida and G. Wu, J. Am. Chem. Soc., 2008, 130, 3590-3602.

100 G. Wu and A. Wong, Biochem. Biophys. Res. Commun., 2004, 323, 1139-1144.

101 A. Wong, J. C. Fettinger, S. L. Forman, J. T. Davis and G. Wu, J. Am. Chem. Soc., 2002, 124, 742-743.

102 G. Wu and A. Wong, Chem. Commun., 2001, 2658-2659.

103 D. Rovnyak, M. Baldus, G. Wu, N. V. Hud, J. Feigon and R. G. Griffin, J. Am. Chem. Soc., 2000, 122, 11423-11429.

104 A. Wong and G. Wu, J. Am. Chem. Soc., 2003, 125, 1389513905.

105 A. Wong, F. W. Kotch, I. C. M. Kwan, J. T. Davis and G. Wu, Chem. Commun., 2009, 2154-2156.

106 G. Wu, A. Wong, Z. H. Gan and J. T. Davis, J. Am. Chem. Soc., 2003, 125, 7182-7183.

107 R. Ida and G. Wu, Chem. Commun., 2005, 4294-4296. 